\title{
Research on Technological Innovation of the Toll Road Industry----Based on the Perspective of Value Chain Management
}

\author{
Xia Zhang \\ Xi'an, Chang'an University \\ Xi'an, Shan Xi, 710064 \\ zhangxia@chd.edu.cn
}

\author{
Wu-Juan Liu \\ Xi'an, Chang'an University \\ Xi'an, Shan Xi, 710064
}

\begin{abstract}
In the operation process of the toll road industry, compared to cash flow and logistics, information flow plays a more important role. It runs through every link of the industry value chain and provides guarantee and support for the increase of the additional value of value chain. From the perspective of value-chain management and its strategic application, this paper studies the virtual value chain architecture of the toll road industry, analyzes the stage characteristics and the existing problems of the informatization development of toll roads, and emphatically puts forward ideas on the technological innovation of the toll road industry based on the virtual value chain.
\end{abstract}

Keywords-toll road industry, technological innovation, value chain management

\section{INTRODUCTION}

At present, researches relating to technological innovation of our country's academia are mainly focused on the areas of technological innovation and economic growth, technological innovation and economic restructuring, technological innovation and industrial organization evolution, etc. Domestic and foreign researches show that the application of new technologies will form new industry groups, can also produce a corresponding industrial organization form. A large number of information technologies have been applied to the traditional industries' technological innovation, organizational innovation, management innovation, etc., which makes original production technologies have the information, intelligentization and networking and other characteristics, and form advanced enterprise manufacturing technologies and production management modes. In the operation process of the toll road industry, compared to cash flow and logistics, information flow plays a more important role. It runs through every link of the industry value chain and provides guarantee and support for the increase of the additional value of value chain. From the perspective of value chain management and its application strategy, study the industry technology innovation ideas in toll roads. As regards to the strengthen of virtual value chain management in charging industry, conduct further coordination management on the physical value chain for each link, and finally enhance the industrial competitive advantage, promote the competitiveness of the industry.Combined with the informatization construction of the toll road industry, this paper puts forward technology innovation strategies of the toll road industry based on the virtual value chain management. The difficulties of the study lies in: The architecture of the virtual value chain of toll roads industry. Toll roads industry technology innovation thought base on the value chain management and its application strategy, which are the focus of the article.

\section{INFORMATIZATION OF TOLL ROADS AND THE} CONSTRUCTION OF VIRTUAL VALUE CHAIN OF THE TOLL ROAD INDUSTRY

Informatization of toll roads refers to that use various high and new technologies to collect and dispose all kinds of traffic information systematically in respect of the planning, construction, maintenance, operation and management and other aspects of toll roads, with a view to share information resources and improve the management and service level. It includes five major areas, namely infrastructure construction and management informatization of toll roads, traffic production management informatization of toll roads, product marketing informatization of toll roads, science and technology informatization of toll roads and government informatization of toll roads [11].

Michael Porter [12] (1985) points out that the main strategy of the industry value chain management is decomposition, integration, collaboration and strategic alliance. Virtual value chain achieves appreciation through the collection, organization, selection, synthesis and distribution of information, and each value-added link of the virtual value chain management can create value. From the perspective of information flow and system function realization, toll road industry informatization can be divided into three aspects, namely the road network planning, construction, maintenance and maintenance, road management, traffic management, fee management, information services and other aspects. From the perspective of information flow and system function realization, the informatization system of the toll road industry can be divided into three levels: the information source, the information sharing and processing and the system function realization. The informatization system of the toll road industry includes four big subsystems and one platform, namely, road management system, traffic 
management system, road toll system and traffic information system and road network communication platform. Accordingly, the virtual value chain of the toll road industry can be shown as Fig. 1.

According to the above analysis, the road management system is the core business in the virtual value chain of the toll road industry, and the subsystems should be constructed according to the integration idea, and be integrated to play the overall advantage; traffic information system is usually combined with the road network traffic information platform and is the platform for sharing and exchanging information between application systems; the key of road toll system now is how to integrate.

\section{Stage Characteristics AND ITS DeVElopMENT GOALS OF TOLL ROAD INFORMATIZATION DEVELOPMENT}

\section{A. Stage Characteristics and Problems of toll Road Informatization Development}

At present, in our country, toll roads not only widely use toll, monitoring and communication systems, but also strengthen the business system construction and effective application of pavement management, bridge management, road administration management, maintenance management, engineering construction, etc., also further develop and construct the road database and other basic information resources, and set up a road information management center. Toll road informatization construction and effective application greatly enhance the management level and improve the work efficiency, but compared to the development demands of the transport industry informatization, there is still a certain gap. Specifically in: In the aspect of road information infrastructure construction, the structure and capacity of the existing backbone network cannot meet the requirements of the information networking management, and the security of the network system needs to be improved. In the process of the construction, operation, management and maintenance of the information system, standardized and institutionalized information management mechanism and information sharing mechanism need to be improved, and the planning, standard and specification of information resources lag behind; the development of technical support, staffing, funds investment, network construction and application level are not balanced [3].

\section{B. Energy Efficiency and Value Chain Management Goals of Toll Road Informatization}

The informatization and intelligentization of the toll road industry are an important part of the framework of the national intelligent traffic system. The intelligent traffic system is the advanced stage of the informatization development of the toll road industry. The toll road network planning, road construction, traffic management, operational management and other systems covered by the informatization and intelligentization of the toll road industry should coordinate and unify mutually. Through informatization construction, change operational modes and processes, processes to improve the efficiency of information collection, data processing, statistical analysis, etc. Finally, intelligent technologies such as fuzzy logic, neural network and expert system are applied to realize the intelligentization of information processing, judgment, prediction and decision-making support, etc., and improve the scientificity and intelligent level of management and decision-making.

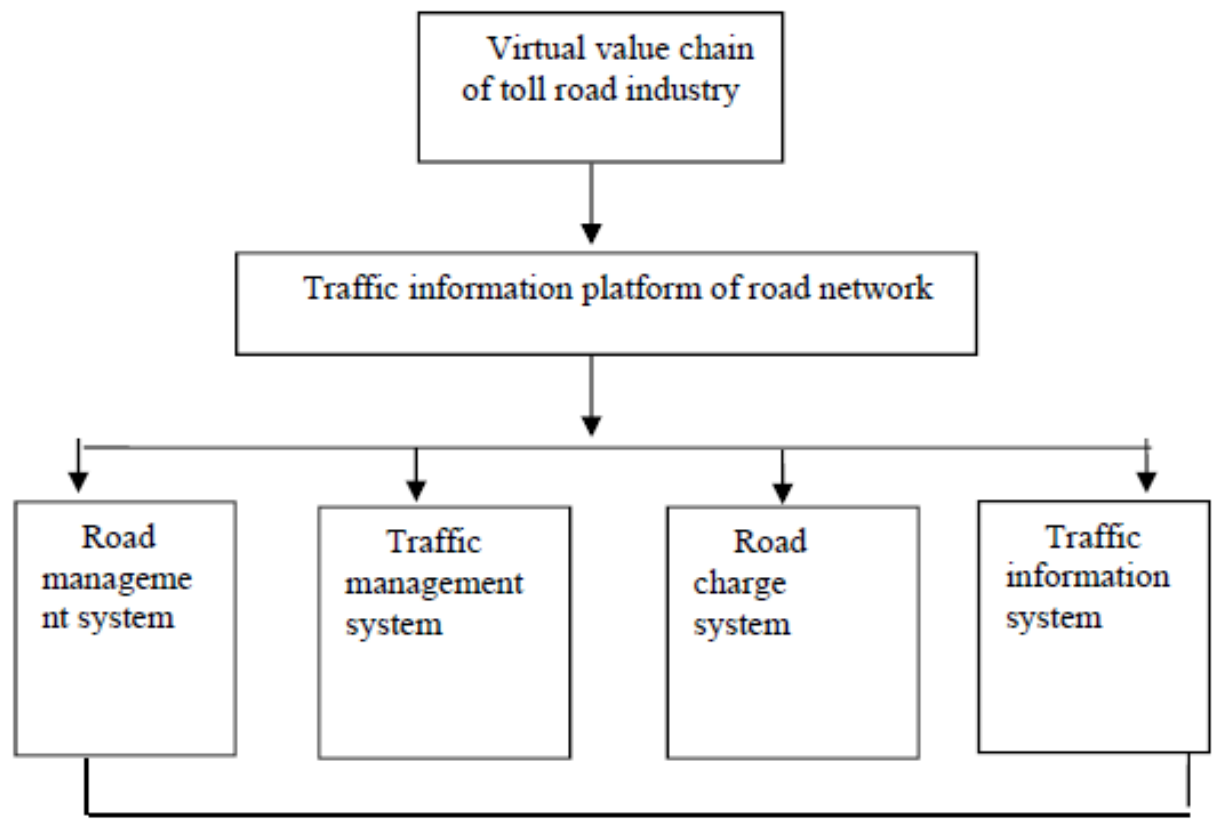

Figure 1. Virtual value chain of the toll road industry 
The basic ideas of industrial value chain management are oriented by the demands of the market and customers, and the modes of operation are the cooperative competition and multi-win principle. Through the use of the management ideas, methods and information technology, network technology, integration technology of modern enterprises, realize the effective planning and control of the information flow, logistics, capital flow, value flow and work flow of the entire supply chain. The virtual value chain is a dynamic reflection of the activities of the physical value chain, and the virtual value chain can penetrate into all aspects of the physical value chain and serve for it. The goals of the toll road informatization system are to build a complete, efficient and intelligent informatization and intelligentization system of the toll road industry, form the road network intelligent traffic system, achieve the unification and intelligentization of the planning, construction, maintenance and conservation, traffic management and other aspects of the entire road network, and promote the integration of regional road network traffic management.

Strengthening the virtual value chain management of chargeable industries can coordinate and manage the various links of their physical value chain to produce synergies, reduce redundant processes, reduce transaction and management costs, and increase the value for users and themselves, can change information's asymmetric weaknesses in the market of the toll road industry, optimize market structure within a greater range, and greatly enhance the additional value of products, obtain differentiated advantages, which make industrial output structures tend to high additional value, technology structures tend to high and new science and technology, market and trade structures shift to diversification, and industrial organizations transform from deconcentration to concentration. The ultimate goals are to strengthen the industrial competitive advantages and enhance the industrial competitiveness.

\section{TeChNOLOGICAL InNOVAtion OF THE TOLL RoAD INDUSTRY BASED ON VIRTUAL VALUE CHAIN}

With regard to the development of technological innovation of the toll road industry based on virtual value chain, it is necessary to introduce the advanced management mode and optimize the management method to realize the modernization of toll road informatization management, scientification of decision-making, intelligentization of network dispatching and service socialization.

The first is to strengthen the informatization infrastructure construction, establish a standardized information resource sharing system, integrate the existing and under-construction information resources, establish a information platform that integrates data collection with road network analysis, etc [1].

The second is to establish a unified standard and specification for informatization technologies, strengthen the development and transformation of existing application systems, integrate the e-government, website platform and internal LAN, achieve the office networking, government affairs opening and road service information standardization as soon as possible, and lay a good foundation for promoting the informatization construction.

The third is to attach great importance to the training of professionals of road information, in particular, focus on cultivating complex talents who understand the road business and information technology, strengthen the training of existing personnel, and improve the overall quality of practitioners of the road industry.

\section{CONCLUSION}

The creative point of this research article is to study the architecture of virtual value chain and technology innovation of toll roads industry from the perspective of value chain management and its application. To use value chain management ideas and promote the informatization and technological innovation of the toll road industry, we should give full play the penetration, diffusion and multiplication effects of the virtual value chain, apply informatization and technological innovation to develop traffic information resources, achieve the effective sharing of information resources, and improve the overall strength and competitiveness of the toll road industry.

\section{ACKNOWLEDGMENTS}

Fund Project: Project funded by the special fund of the basic scientific research business fee of Central University of Chang'an University: "Research on Expressway Project Risk Management Based on PPP Mode" (Project No.: 310823151008).

\section{REFERENCES}

[1] Zhang Ji. Analysis of How to Realize the Informatization Operation Management of Expressway [J], Construction Engineering Technology and Design, 2016, 08

[2] Ding Guihua. Exploration of Expressway operation and management information construction and programs $[\mathrm{J}]$. Northern Economy and Trade, 2015(7.)

[3] Ou Jushang. Problems and Countermeasure Analysis of Expressway Traffic Management Informatization Construction [J], Journal of Chongqing Traffic College, 2S013, 14(01)

[4] Zhang Wei. Intelligent Analysis of Expressway [J]. China Traffic Informanization, 2012,

[5] Xu Maosheng, Modern Communication Technology Research and Application [J], Commodity and Quality Science Theory, 2011, 24 (05)

[6] Zhou Zheng. Expressway Network Communication Technology and Its Realization Methods, Henan Technology, 2010, 39 (03).

[7] Arnold van Zyl.ITS Development in Europe[C].Closing PanelDiscussion:ITS Vision 2020,14th World Congress on ITS,Beijing,2007

[8] Xu Yan,Yang Xiao-kuan,Rong Jian,Liu Xiao-ming.The Approach of Developing ITS Architecture for Beijing 2008 Olympics Based on Turbo Architecture.the 12th World Congress on ITS.2005.11

[9] Sanduo Zhou, Chuanming Chen etc. Management science. Higher education press, 2003(9).

[10] Xinhua Jan, Shan Wei. Industrial economics. Wuhan University 
[11] Wang Liming, Value chain management and strategic alliance [J], Journal of Shanxi University of finance and economics, 2001
[12] Michael Porter, the competitive advantage (M), Beijing: Huaxia publishing house, 1997 